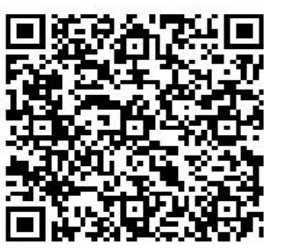

\title{
SHOULD WE FRAME GENDER QUESTIONS DIFFERENTLY?
}

\section{Etienne Rassendren*}

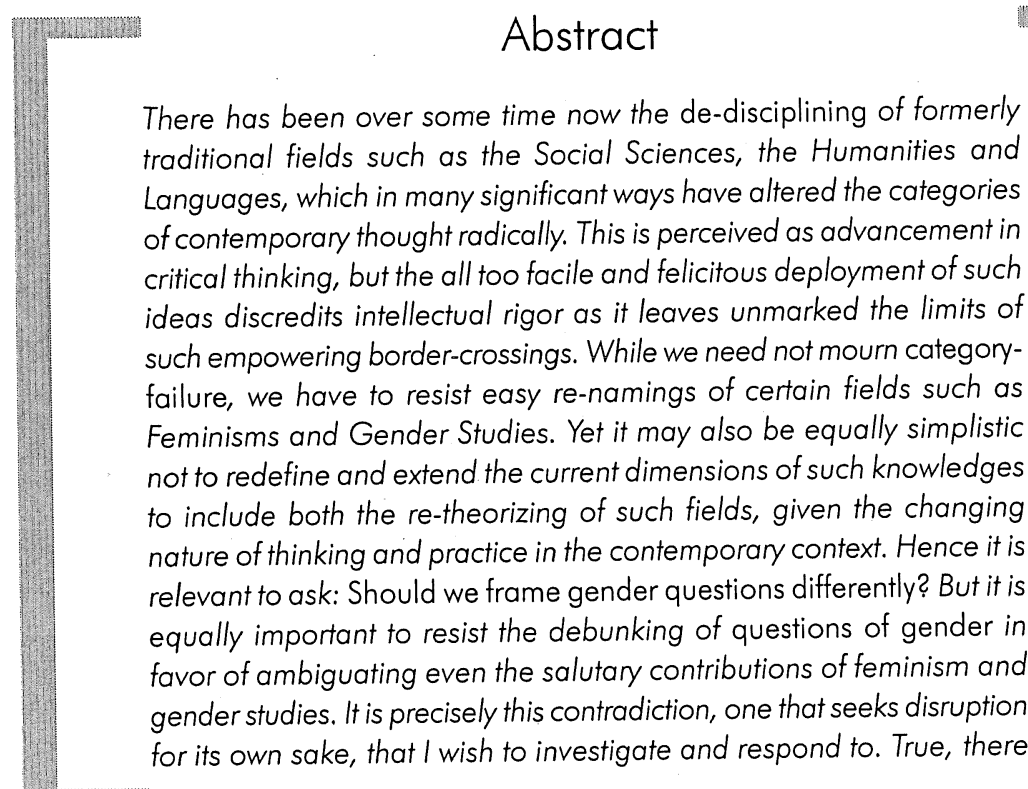

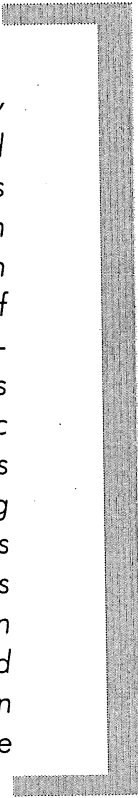

\footnotetext{
* Department of English, St Joseph's College, Bangalore
} 
will be more questions than answers in this respect but it is precisely those I wish to raise in the current article.

Keywords: Gender, Masculinization, Reframing

\section{Introduction}

It is true that the rather traditional fields of the Social Sciences, Humanities and Languages are being torn down by the interdisciplinary bluring of already established categories. The enlightenment idea of category-failure mourned by consummate conservatives appears to have receded into what many contemporary intellectuals call inter-subjunctivity, meaning the inter-textualizing of a wide variety of highly differentiated knowledges. Yet there is the unmistakable intellectual rub, when the limits of such erosion of critical categories or fields are left unmarked. While the de-disciplining of disciplines is salutary and productive indeed, the all too facile deployment of the practice of ambiguation with its simplistic felicity merely discredits intellectual and critical rigor particularly related to certain elaborate archives of assumably tested and simultaneously emergent fields such as Feminism and Gender studies. It is perhaps in the tenuous moment of both the exciting transition of disciplinary critiques causing empowering border-crossing dynamics and the conservative discontent with abandoning established fields of study that we must ask the question: should we frame gender questions differently?

As we acknowledge that no discipline of study, no category of thought, no structure of perception can any longer exclude or opt out of considering gender as a key question and issue for analysis and action-particularly because of the sustained and stirring efforts and struggles of feminist thinkers and activists- we have also to recognize that there is a rather disquieting recuperation of a neo-liberal conservatism that restores gender questions as social commonsense. One hears women students in some of our liberal classrooms call feminism just an "intellectual frill" or "too much women". That often amounts to little or nothing in the larger scope of critical thinking.

One also listens to demands for more male participation, for more male teachers to teach the humanities, because there are too many women doing that work, producing an almost skewed neo-biologicism, so systematically contested by feminists the world over. Even if gender is everywhere ${ }^{3}$ as we know it is and as we represent it as such, one is faced with a resurgent denial and submergence of gyno-centricity in the name of private choice of the "gender-neutral" humanist subject". Much 
after the Derridean critique of foundationalism and the Foucauldian dismembering of ethics ${ }^{5}$ both extremely salutary strategies of thinking, there appears a tendency to deploy these productive process in a felicitous often contradictory style that verges on fetishized traditionalism or bourgeois laissez-faire. It therefore requires us to break this misplaced critical commonsense by talking, thinking and acting about/ on questions of gender differently — different from the strategies we have used to conceptualize gender issues and represent gender questions. Hence what I wish to do here is to map and delineate two seemingly unconnected issues in our conceptualization and representation of gender-related concerns using certain case studies, often stories of women's experience in our contemporary context. In this respect I also wish to place the questions as ultimately at the centre of discussing questions of gender. At the end I wish to argue for an altered depiction of genderrelated issues as a strategy of intervention in the sexual-politics of contemporary social space.

\section{Gender and the Problem of Representation}

There are a variety of social codes and practices that are deployed by ideologies and their agencies to structure together gender as key strategy for sustaining patriarchy. Often these are cast and recast in multiple cultural modes in order to maintain the often marginal and sometimes violated place and position of women in our social sphere. Chief among these patriarchal strategies is the covert and /or overt restoration of two most repressive processes of gendering namely, the regulation of sexual desire on the one hand and the exploitation of the woman's body on the other ${ }^{6}$. This is achieved by a sinister media-driven mechanism of image-building foregrounding women in the public sphere as if there are more women becoming producers of their own destinies: representing women as becoming small entrepreneurs, if not big ones, in charge of their own economic well-being; women as using freely their creativity to becoming upwardly mobile battling away both caste and gender simultaneously; traveling freely with friends, male and female, without either patriarchal regulation or sexually assaulting males, regulating their social mixing; as not bearing their caste-marks ${ }^{7}$ and being admitted to professional and non-professional education irrespective of class/ caste position. But while the media produces this image of the advancing/achieving woman, they also continue to report contradictorily the rise in crimes against women that are either based on masculinist regulation of women's bodies or the spectacularization of the women's bodies in the male gaze.

I wish to illustrate this point a little further invoking two rather instructive instances of such regulation that uses the method of sexual spectacle. Recently the State had 
attempted to legislate the banning of women working the night shift as a means of providing security and good governance to its citizens. In its claim it stated that traditionally women never worked the nights and in the now changed circumstances needed to be protected from sexual abuse, assault and sexual harassment including rape and murder. While its intents appear salutary, the state conceptualized the problem of sexual harassment in the workplace and in the public sphere in terms of the normativeness of tradition and culture, of protection from and prevention of male sexual excess on the vulnerability of women. If we make a Saussurean connection here, this habit fore-grounds reductively the woman as mere body. This simultaneously retuned the women to their private household spaces, denying them the right to work within the changed economies of the present. This in every sense configures the woman as spectacle guaranteeing the male gaze its continued power, while restoring the coercive inside of household spaces. By that token, this attempted legislation attempted to re-constitute the nationalist ideal that Pratha Chatteriee in his analysis of the women's questions in nationalism discusses. Chatterjee claims that women's "self-emancipation" had been submerged in the rise of nationalist ideologies as the male anti-colonial combatant restored "feminine virtues" of "housework", "chastity", "devotion" and "self-sacrifice" of upper caste Hinduism as norm of superior "Indian" culture and spirituality ${ }^{8}$. It is precisely this recuperation of the national as a patriarchal preservation and protection of culture and spirituality on the sites of family, kinship and the home that one recognizes in the attempted legislation of the state in the present. What is interesting to note here is how despite globalization with all its fanfare in modernity, ideological spaces continues to redeploy traditional patriarchy with all its implications in masculinized division of labor

What is more instructive however is how the male fear of female sexuality breeds regulation of the woman's body, and the privatization of women's sexuality as cultural property in the service of a utopian nationalism, controlled by the masculinity of patriarchal agency. The State chooses to constitute the issues of sexuality in the public sphere as matters of the private security of individual women than as questions of gender integral to the patriarchy of the state.

The next instance concerns the interconnection between sexual desire, male violence and female subordination in the conjugal space. In a rather incisive article on the issue of conjugal violence $V$ Geetha ${ }^{9}$ argues that often sexual violence on the women's body has been enclosed within the domestic sphere and is often accompanied by the erotics of male power. Most of the time such violence concerns the position the male figure occupies within the space of family, a position often constituted by modes of sexual control and sometimes of economic uncertainty but also of cultural power. It is in fact a complex terrain in which the erotics of "loving...controlling... and possessing the body of the wife" is associated with a 
"vicious logic of domination" in relation to "family honor" and its attendant ideologies ${ }^{10}$. If one reads media stories about domestic violence, one is faced with how suspicion and wife-battering attend the sexual-politics of inscribing the women's body. The suspicion in most cases concerns the economics of class as the perpetrators of violence are often identified apparently with either a higher or a lower class position. " Given the caste-marks of male batterers, there is a further complication that suggests the enclosing of caste boundaries. The wife turning hostile at court refusing to name the violator often relates to the "self-loathing" and "guilt" that inverts the logic of domination into an affirmation of erotic "interest" and "monogamy"12"

What is instructive here is the politics of sexual possession being located in the conjugal space. The place of the battered wife is located within the terrain of property and as an object of ownership that deploys a terrorizing eroticism in an expression of male authority. The intersection of caste and class on the site of violence transacts a fundamental burden of simultaneous sexual labor and regulation on the woman's body submerging female desire through either imagined or real suspicion of sexual promiscuity. Since the conjugal space blurs into the public sphere of economic deprivation and/or success, the family as an institution becomes the space for the development of a sexual economy that divides sexual labor and erotic love as property through the processes of violence authority and control of the woman's body.

What I have attempted to disclose in this segment is the structuring of patriarchal male power, not just in its individual mobilization but in terms of larger system of ideological agency as it sutures together violence and regulation on the female body. In this respect, the exploitation of the sociality ${ }^{13}$ of the women-that is the sum total of her cultural and economic spaces-and the sexual politics of conjugal and kinship spaces intersect with questions of caste and class in the contemporary context. What is most visible is that no longer can we talk about gender except through an altered optic of perception that includes but de-aggregates simultaneously the interstices of sexuality, domestic space and the public sphere. In the current context however there is a critical tendency that conflates the one for the other submerging the one with other, rather than analyzing the convergence between the politics of protection and the culture of regulation on the body. Not surprisingly then it is often in the name of self-emancipation and cultural preservation that some of the worst forms of repression are organized -as in the cases of State legislations, and the domestication of sexual violence earlier analyzed. This in an indirect sense brings us to the politics of representation of gender issues which then begs the question: what should be the analytical optic with which we examine questions of gender? Should we abandon the more universal formulations of gender 
questions that displace the specificity of our locations and the altered nature of our current context?

\section{Fundamentalism and Gender:}

In this segment what I wish to consider is the rise of fundamentalism and the way in which it translates sexual-politics in the contemporary context. While we may necessarily assume that Hindutva and its proponents carry the political agenda of Hindu Rashtra, a specific form of othering, as it were - the varied minorities in the Indian nation being the privileged object of violence - is reserved for the Muslim minority, represented as not belonging here because of its assumed alliance to Pakistan, the nation's closest enemy. As this political discontent and cultural hate brews, one begins to notice the transaction of systematic forms of communal pogroms taking on vastly unprecedented proportions in the nation state. One immediately remembers Godhra 2002 as the hegemonic laboratory of the imagined Hindutva State and later Kandhamal 2008 as the Hinduizing absorption of tribal-dalit communities. While Kandhamal is separate case here, I will reserve the discussion for Godhra 2002

Godhra 2002 is not merely a spontaneous eruption of majoritarian anger against minority arrogance and/or appeasement. It is part of a larger history of Hindutva politics that begins in the interlocking of cultural and political forces in the Ramianmabhoomi/anti-Mandal movements of the 1990s. It is here that the intellectual rub for feminist thinking in "India" emerges. Let me gesture here one of most central analyzes of the of Hindutva history made by Susie Tharu and Tejaswini Niranjana in their article titled "Problems for a Contemporary of Gender". Published first in the Social Scientist in 1994, this article on "Indian" feminism's problems to articulate and represent an inclusive analytical optic to represent gender in the changed context of a communalized polity has been repeatedly published for its powerful questioning of upper caste/middle class modes of theorizing gender, without attention to a variety of constituencies, including Islamic women and dalit gendered informants. They locate what may be called an analytical "impasse" in the realignments of feminist dynamics and discourses with universalist structures of domination. This participation of autonomous women, not necessarily as "daughters,/wives of their political fathers/husbands as productive self-articulating and self-recognizing agents of their subjectivity and power in political movements produces the "feminist subject" still marked by a radical right wing "humanism" and situated within the class/caste/community axis. In other words there as been a displacement of the politics of the upper caste/middleclass axis onto the universalized feminist subject that recognizes middle class/ upper caste women as the "authentic 
bearers of secularism and egalitarianism 114 Thus there has been communal class and caste othering of Islamic women of dalit women well within the feminist project in contemporary India. Hence one can only revisit the highly differentiated nature of gendering and hence the need for a highly differentiated optic of gender analysis.

If the Ramianmabhoomi movement constituted the enemy within as the lustful Islamic male ever eager to violate upper caste Hindu women and therefore requiring a productive fight to protect the national ethos from foreign corruption, Godhra 2002 shifts the focus back on the "bystander" women in a variety of forms: in the embodiments of disempowering excuse or tacit approval and sometime vocal support of carnage of Islamic women by such individual women political leaders, parliamentarians and marginally by the NHRC ${ }^{15}$. The problem has been further complicated by the amenability of dalit and adivasi groups to "dangerous and often violent" forms of Hindutva ${ }^{2}$ Somehow there has been a temporal abandoning of the Ambedharkite model of strengthening the "ameliorative" guarantees of the post colonial state ${ }^{16}$ Hence we may have to form modes of analysis that interrogate the "hidden structuring"17 of the feminist subject within a fundementalized context.

There are just two points I wish to make in what this hidden structuring entails. There has been a clear masculinization of Islam as the opposing other of the upper caste/middle class feminist subject which in many ways both lumps the productive Islamic community with the fundamentalist fringes of its own community and also encloses the emerging feminist subject within the Islamic community as absorbed into Islamic patriarchy. This process within the Indian context is produced by the displacement of a Universalized feminist optic that encounters its limits in the contemporary politics of its representation. That apart, it is more than just visible, as Sharmila Regge puts it, that dalit women talk differently from there upper caste counterparts ${ }^{18}$ and western metropolitan feminists. Hence it is impossible to formulate a feminist praxis that transgresses questions of caste, class and community

Concurrently after 9/11 in the Anglo-American world the notion of Islam and its community has shifted from the earlier skewed tolerance of backwardness and tradition to a more active characterization of the community and region as enemies of modernity, freedom and humanity. If one considers the representation of West Asia as deserving modernist self-emancipation from the throes of traditionalist Islam, one discovers the voluntarist sympathy towards women behind the veil marking them as saddened remnants of an ancient regime of female purity. What is certainly not being represented is how the veil itself is not necessarily an Islamic construct but an ethno-Arabic product with a variety of functions, not always regulatory or protectionist but used to inform an aesthetic of dance music and culture. That it is being mobilized by fringe fundamentalists now as a regulatory mechanism of certain 
triumphalist traditionalism in opposition to a flattened consumerist culture that totalizes rather than differentiates deserves to be engaged in. Consider for example the way one talks about the immigrant women in Europe being arrested for wearing their veil in public. Often one notices a fervid sympathy as if they only deserve that. Otherwise one regards them as anti-secular, arch-traditional, incapable of modernity, often even suspect as citizens of any republic. Hence the project of Islamiization of specific geographies of the real and the imagined is structured on the masculinization of the Islamic peoples by Western discourses of power In other words the west feminizes its wars on terror in the name of liberating West Asia from the masculinist clutches of tyranny, traditionalism and fundamentalism.

What once again emerges is that in the discursive process of cultural re-definition, the metropolis continues to enclose the Islamic patriarchies within their own traps of punitiveness and regulation of the woman's body as in the manner of Talibanization of West Asia. Little is offen focused on Islamic women producing their own subjectivity by restoring their own subjectivities in the call to prayer, severely monitored till now by the traditional ullama ${ }^{19}$ This by far is why we are often unable to engage questions of forced sex-work of minor children in Iran and the punitive nature of its regulatory authority as the complicated terrain is undisclosable in the vicious logic of western domination on the one hand and local patriarchy on the other. Hence the representation of Islam and its communities would need to be analyzed in the interstices of the material process of political domination and the localized repressive regulation of female sexuality.

Fundamentalisms thus have had a habit of re-occupying ancient cultural history deploying them as regulatory processes of female sexuality and desire. Often this is in the service of nationalist ideals be it Hindutva or in real or imagined Islamic nations or in the scope of terror in the American neo-liberal state. Thus in this sense gendering is perhaps the foremost terrain on which many of these forms of repression and domination are structured. These are mediated by the convergence of caste, race and class on the one hand and religion, nationality, and the public/ private spheres on the other. What we thus recognize is that the impossible subject ${ }^{20}$ of female presence is heavily underwritten by the politics of sexual regulation of the women's body, the social violation of female desire and the political exclusion of the female subject.

What then is the place of engendering the epistemologies of male power and the historiographies of tradition and modernity? Should we then continue to argue for a temporality of contexts as against the stability of universalities? Should we after all narrativize an ethical frame that will represent women as autonomous subjects of their destinies? 


\section{Conclusion: Rethinking the Frames of Engendering}

Ethics:

From the questions I have raised at the end of each segment, I argue that we need to reframe gender questions to include questions of caste and class, race and nationality and locate the engendering within specific cultural geographies and social contexts. This so principally because we cannot talk about gender without engaging caste in the Indian context; we cannot simply universalize an overarching feminism to answer questions concerning specific nationalities. Hence the need for an altered optic, a different epistemology of gender, is certain, not as felicitous fashion but as a productive process of emergent feminist critical theory I wish to propose three differing processes to reframe questions of gender, while sustaining some of the critical contributions of feminisms.

The first concerns the conflictual terrain of narrativizing the history of female sexuality in terms of its domination and repression. Since most of the global forms of structural violence through religious fundamentalism and other categories such as caste, class, race and nationality are material to historiography, feminist thinking may need to re-occupy by contestation and critique those ancient histories that are used for purposes of repression and domination of the women's bodies while producing counter-lineages of smaller histories. While this might run counter to the progressive thinking in favor of temporality and contextuality and against grand narratives of history, I find the formulation of particularly Hayden White who conceptualizes historicity as ultimately cultural and ethical, deeply resonant ${ }^{21}$. Hence what is perhaps more productive is to interrogate patriarchal histories in an attempt to insert temporalities and contexualities of women's stories as integral to ancient histories.

The second processes concern the restoration of the increased relevance of specific ethnographies, autobiographies and testimonies of women in their self-articulation and self-recognition; and to define gender justice on behalf of the marginalized and suppressed women's position in contemporary contexts. I have in mind here the analytical optics of theorists such as V Geetha, Sharmila Regee and Mary E. John in the mode of focusing gender as a problematic, not in its static and dialectical sense, but as questions concerning more the body - of the woman's body, but not always - than as merely a terrain of theory. In other words one may need to revisit the documentary process and instruments rather than formulate theories about theories thus forcing a re-engagement with the dynamics of patriarchy. This then will refer to the epistemology of an altered body politics as it is represented in current critical thinking. 
The third and final proposition is to seriously consider the question of difference as it is mobilized by different constituencies like the dalit, the racialized and the class-based. That various constituents and agents of female subjects talk differently about their location and absences should occupy a central terrain of social and political inclusiveness in the production of gender questions in the future.

\section{Select Reading list}

John, Mary E and Janaki Nair(Ed) A Question Of Silence? The Sexual Economies Of Modern India New Delhi: Kali For Women 1998

Rao, Anupama (Ed) Sunder Rajan, Rajeswari (Ed. Series) Issues in Contemporary Indian Feminism: Gender and Caste New Delhi: Kali For Women/Women Unlimited 2003/ 2006

Sangari, Kumkum and Vaid, Sudesh Recasting Women: Essays in Colonial History New Delhi: Kali For Women 1989

White, Hayden, The Content Of Form: Narrative Discourse and Historical Representation Baltimore/London The John Hopkins University Press 1987

\section{Journal/ Newspaper articles:}

Tharu, Susie, and Niranjana, Tejaswini "Problems For a Contemporary Theory of Gender" Social Scientist Vol.22, Nos3-4, March-April 1994 p.93-115

Bakshi, Upendra (2002) "The Second Gujarat Catastrophe" in EPW 24/8/2002

The Hindu, Sunday Supplement $6^{\text {th }}$ June 2007

Times Of India Dec 292006

\section{Endnotes}

1 This article is part of the larger research being carried out under UGC Minor Project Scheme(XI Plan) and is titled "Gender and Nation: India and its Narratives and Discourses"

2 Etienne Rassendren has a PhD in English form the Bangalore University and teaches Critical Theory, Gender Studies and Film Studies in St Joseph's College, Bangalore.

3 I am gesturing here the statement "suddenly Women are everywhere" in Tharu, Susie, and Niraniana, Tejaswini "Problems For a Contemporary Theory of Gender" Social Scientist Vol.22, Nos3-4, March-April 1994 p.93-115

4 Sangari, Kumkum and Vaid, Sudesh (1989)" Introduction" Recasting Women: Essays in Colonial History New Delhi: Kali For Women p.3

5 Tharu, Susie, and Niranjana, Tejaswini op. cit. p.93-115 
- I have drawn this idea from John, Mary E and Janaki Nair "A Question Of Silence? An Introduction" in John, Mary E and Janaki Nair(Ed) A Question Of Silence? The Sexual Economies Of Modern India New Delhi: Kali For Women 1998

7 Tharu, Susie "The Impossible Subject: Caste and the Gendered Body" In Rao, Anupama (ed) Sunder Rajan, Rajeswari (Ed.Series) Issues in Contemporary Indian Feminism: Gender and Caste New Delhi: Kali For Women/ Women Unlimited 2003/2006

8 Chateriee, Partha 'The Nationalist Resolution Of the Women's Question" Sangari, Kumkum and Vaid, Sudesh (ed) Recasting Women: Essays in ColonialHistory New Delhi: Kali For Women 1989

9 Geetha, V in John, Mary E and Janaki Nair(Ed) A Question Of Silence? The Sexual Economies Of Modern India New Delhi: Kali For Women 1998

10 Ibid., Geetha, V in John, Mary E and Janaki Nair(Ed) 1998

"I have in mind numerous media stories but the one that I refer to here is found in Ibid Geetha, $V$ in John, Mary E and Janaki Nair(Ed) 1998

$12 \quad$ Ibid., 1998

$13 \quad$ Ibid.' 1998

14 Tharu, Susie, and Niranjana, Tejaswini op.cit 1994 p.93-115

15 Bakshi, Upendra (2002) "The Second Gujarat Catastrophe" in EPW 24/8/2002 p.3525

16 Rao, Anupama 2003/2006) op.cit p.34

17 Tharu, Susie, and Niranjana, Tejaswini op. cit. 1994 p.97

18 Regge, Sharmila "A Dalit Feminist Standpoint" in Rao, Anupama(2003/2006) op.cit p. 96

19 For details, See The Hindu, Sunday Supplement $6^{\text {th }}$ June 2007

so Tharu, Susie in Rao, Anupama(2003/2006) op.cit p.34

2) White, Hayden, The Content Of Form: Narrative Discourse and Historical Representation Baltimore/London The John Hopkins University Press 1987 